\title{
Estimativa da similaridade genética e identificação de cultivares do mo- rangueiro por análise de RAPD
}

\author{
José Henrique Conti; Keigo Minami; Luiz Humberto Gomes; Flavio Cesar A. Tavares \\ USP-ESALQ, C. Postal 09, 13.418-900 Piracicaba - SP. Email: jhconti@hiway.com.br
}

\begin{abstract}
RESUMO
Caracteres moleculares do morango foram avaliados para conhecer cultivares que estão sendo introduzidas no Brasil. Utilizouse o método do polimorfismo de DNA amplificado ao acaso (RAPD). Os caracteres moleculares com maior poder de discriminação foram os "marcadores" gerados pelos "primers" Operon B8, Operon B19 e Operon G5, que foram eficientes para discriminar as vinte e seis cultivares estudadas. Os dados foram interpretados com o auxílio de dendograma, mapa de bandas, quadro de identificação e chave dicotômica. Foi possível distinguir seis grupos de similaridade, dois deles com cultivares selecionadas no Brasil, sendo um com 'Campinas', 'Agf 80', 'Piedade', 'Jundiaí' e 'Monte Alegre' e o outro com 'Obaira' e 'Mantiqueira'; três grupos com cultivares introduzidas, sendo o primeiro com 'Lassen', 'Reiko', 'Chandler', 'Pajaro', 'Blackmore' e 'Seascape', o segundo com 'Fern' e 'Oso Grande' e o terceiro com 'Florida Belle' e 'Selva' O último grupo reuniu as cultivares 'Dover' e 'Dabreak' junto com 'Princesa Isabel'.
\end{abstract}

Palavras-chave: Fragaria X ananassa Duch., marcador molecular, germoplasma.

\begin{abstract}
Estimate of the genetic similarity and identification of strawberry cultivars by RAPD analysis

Strawberry cultivars introduced in Brazil were identified through molecular study. The method of Random Amplified Polymorphic DNA (RAPD) was used. Molecular characters with larger discrimination power were produced by the primers Operon B8, Operon B19 and Operon G5. These were efficient to discriminate the twenty six studied cultivars. Data were analised through dendogram, bandmap, picture and dicotomic key. Six similarity groups were distinguished: Two with cultivars selected in Brazil, one with 'Campinas', 'Agf 80', 'Piedade', 'Jundiaí' and 'Monte Alegre' and the other with 'Obaira' and 'Mantiqueira'; three with introduced cultivars the first of which 'Lassen', 'Reiko', 'Chandler', 'Pajaro', 'Blackmore' and 'Seascape', the second with 'Fern' and 'Oso Grande' and the third with 'Florida Belle' and 'Selva'. The last group united the cultivars 'Dover' and 'Dabreak' with 'Princesa Isabel'.
\end{abstract}

Keywords: Fragaria X ananassa Duch., molecular marker, germplasm.

(Aceito para publicação em 04 de abril de 2.002)

\begin{abstract}
$\mathrm{A}$ maioria das cultivares de morangueiro originou-se de poucos ancestrais (Scott \& Lawrence, 1975) e o melhoramento genético tem estreitado ainda mais a base genética do morango cultivado (Sjulin \& Dale, 1987). São poucas as informações sobre a diversidade do germoplasma disponível em programas de melhoramento e a origem dos materiais não parece estar correlacionada com a diversidade genética. Assim, o sucesso no desenvolvimento de novas combinações de caracteres em futuras cultivares de morangueiro pode ser limitado pela falta de informações e pela baixa diversidade genética (Graham et al., 1996). A introdução de cultivares, a produção de mudas e o patenteamento de cultivares necessitam de sistema de identificação. A caracterização de cultivares é a base para trabalhos de estimativa de similaridade genética e para a sua identificação.
\end{abstract}

Atualmente a identificação de cultivares do morangueiro no Brasil é baseada em características morfológicas. O registro institucional de cultivares do morangueiro baseia-se em trabalho de Passos et al. (1994) onde são descritas as características morfológicas que devem ser consideradas na caracterização de cultivares. Os trabalhos de Nehra et al. (1991) e Bringhurst et al. (1981), que utilizaram a análise de proteínas, demonstraram que $\mathrm{o}$ número de "marcadores" isoenzimáticos possíveis é pequeno, confirmando a opinião de Ferreira \& Grattapaglia (1996) que o número de locos isoenzimáticos disponíveis limita o poder desta técnica. Proposta por Williams et al. (1990), a técnica de Polimorfismo de DNA Amplificado ao Acaso (RAPD) demonstrou ser eficiente na identificação de cultivares do morangueiro nos trabalhos de Parent \& Pagé (1995); Gidoni et al. (1994) e Graham et al. (1996).
O presente trabalho visou a caracterização molecular, via RAPD, de vinte e seis cultivares de morangueiro, nacionais e introduzidas, incluindo as atualmente cultivadas e aquelas com potencial de uso em programas de melhoramento e nas diferentes regiões produtoras.

\section{MATERIAL E MÉTODOS}

As vinte e seis cultivares de morangueiro, fornecidos pelo IAC, foram mantidas em vasos, coletando-se as amostras de folhas utilizadas na caracterização molecular. As cultivares foram numeradas de 1 a 26 . A Tabela 1 descreve as cultivares, o respectivo número indicativo, o país de origem e os marcadores que as identificam.

Em cada cultivar foram coletadas uma ou duas folhas "não expandidas" que foram colocadas em cadinho de porcelana onde foi adicionado nitrogê- 
Tabela 1. Cultivares organizadas pela mesma ordem em que aparecem no dendograma e os respectivos códigos de identificação, Estado e país de origem e "marcadores" que identificam as cultivares.

\begin{tabular}{|c|c|c|c|}
\hline Código & Cultivar & Local de origem & "Marcadores" \\
\hline 1 & 'Dover' & Flórida/EUA & B19E (+), B19M (-), B8I (-) \\
\hline 4 & 'Princesa Isabel' & São Paulo/Brasil & $\mathrm{B} 19 \mathrm{~V}(+), \mathrm{B} 19 \mathrm{P}(+)$ \\
\hline 10 & 'Dabreak' & California/EUA & $\mathrm{B} 8 \mathrm{G}(+)$ \\
\hline 2 & 'Agf 80' & São Paulo/Brasil & B19M (+), B19E (-), B19F (-), B19W (-), B19R (-) \\
\hline 3 & 'Campinas' & São Paulo/Brasil & B19M (+), B19E (-), B19F (-), B19W (-), B19R (-) \\
\hline 7 & 'Jundiai' & São Paulo/Brasil & B19E(-),B19W(-),B19R(-),B19J(-),B8I(+),B8O(-), G5A (+) \\
\hline 6 & 'Piedade' & São Paulo/Brasil & B19R (+), B19W(-), B19L (-) \\
\hline 11 & 'Monte Alegre' & São Paulo/Brasil & B19W (+), G5N (-) \\
\hline 23 & 'Chandler' & California/EUA & B8J (+), B19E (-) \\
\hline 26 & 'Seascape' & California/EUA & B19F (+), G5D (-) e B8J (-) \\
\hline 9 & 'Lassen' & California/EUA & B19E (+),B19M (-),G5C (-),B8J (-),B8I (+),B19J(+) \\
\hline 25 & 'Blackmore' & California/EUA & B19M (+), B19E (+), B8G (-), B19V (-) \\
\hline 13 & 'Reiko' & Japão & B19E(+),B19M(-),G5D (-),B8I (+),B19J (-),G5A (+) \\
\hline 24 & 'Pajaro' & California/EUA & B8J (+), B19E (+) \\
\hline 5 & 'Guarani' & São Paulo/Brasil & B19V (+), B19P (-) \\
\hline 16 & 'Sequoia' & California/EUA & G5C (+) \\
\hline 8 & 'Cruz' & Flórida/EUA & G5N (+), B8L (-) \\
\hline 17 & 'Florida Belle' & Flórida/EUA & B19l (+) \\
\hline 19 & 'Selva' & California/EUA & G5A (+), B19E (-), B19L (-), B8L (-), B8I (-) \\
\hline 14 & 'Dr. Morèrè' & França & $\mathrm{B} 19 \mathrm{~L}(+)$ \\
\hline 12 & 'Obaira' & São Paulo/Brasil & B19E (-), B8I (+), B8O (+), B8B (-) \\
\hline 15 & 'Mantiqueira' & São Paulo/Brasil & $\mathrm{B} 19 \mathrm{E}(-), \mathrm{B} 8 \mathrm{I}(+), \mathrm{B} 8 \mathrm{O}(+), \mathrm{B} 8 \mathrm{~B}(+), \mathrm{B} 19 \mathrm{I}(-), \mathrm{G} 5 \mathrm{~N}(-), \mathrm{B} 19 \mathrm{~F}(-)$ \\
\hline 22 & 'Toyonoka' & Japão & G5D $(+)$ \\
\hline 18 & 'Fern' & California/EUA & B19E (-), B8I (+), B80 (-), G5A (-) \\
\hline 21 & 'Oso Grande' & California/EUA & B19E (+), B19M (-), B8I (+), G5A (-) \\
\hline 20 & 'Korona' & Holanda & B8L (+) \\
\hline
\end{tabular}

nio líquido. As folhas foram maceradas com pistilo até a formação de um pó bem fino. Deste material colocou-se 100 a $150 \mathrm{mg}$ em tubo de Eppendorf. Em um dos tubos foi adicionado $650 \mathrm{ml}$ do tampão de extração ( $3 \%$ CTAB, $1,4 \mathrm{M}$ $\mathrm{NaCl}, 20 \mathrm{mM}$ EDTA, $100 \mathrm{mM}$ Tris Hcl $\mathrm{pH} 8,0,1 \%$ polivinilpirrolidone) contendo $40 \mathrm{ml}(6,0 \%)$ de 2-mercaptoetanol adicionado imediatamente antes do uso. Os tubos restantes, com material extraído, foram armazenados em freezer à temperatura de $-70^{\circ} \mathrm{C}$. Os tubos foram incubados em banho Maria a $60-65^{\circ} \mathrm{C}$ por 30 minutos. Durante a incubação, os tubos foram agitados a cada $10 \mathrm{mi}-$ nutos para homogeneizar a suspensão. Após a incubação foi adicionado $650 \mathrm{ml}$ de solução de clorofórmio-álcool isoamílico (24:1), agitando-se os tubos a cada 5 minutos e invertendo-os até formar emulsão homogênea. Os tubos foram centrifugados a $13.000 \mathrm{rpm} \mathrm{du}$ rante 10 minutos. A face superior foi pipetada para outro tubo, onde foi adicionada novamente solução de clorofórmio-álcool isoamílico (24:1), agitado e centrifugado novamente. Posteriormente adicionou-se $150 \mathrm{ml}$ de solução de acetato de amônia $5 \mathrm{M}$ e em seguida adicionou-se $1000 \mathrm{ml}$ de etanol $96^{\circ} \mathrm{GL}$ à temperatura de $-20^{\circ} \mathrm{C}$ para precipitar os ácidos nucléicos no fundo do tubo. O tubo de Eppendorf foi invertido e mantido nesta posição por aproximadamente 20 minutos, até evaporar o etanol. Foram realizadas duas lavagens dos ácidos nucléicos adicionando, em cada uma delas, $300 \mathrm{ml}$ de etanol $70 \%$. O tubo foi invertido e aguardado o tempo necessário para que o "pellet" e o tubo ficassem completamente secos. O "pellet” foi ressuspendido, dependendo do tamanho, em 50 a $100 \mathrm{ml}$ de tampão TE (10 mM Tris $\mathrm{HCl} \mathrm{pH} 8,0$ e 1,0 mM EDTA), até ficar completamente dissolvido.

Para a eliminação do ácido ribonucléico adicionou-se aos tubos 2 $\mathrm{ml}$ de solução de RNAse $(10 \mathrm{mg} / \mathrm{ml})$ para cada $100 \mathrm{ml}$ de solução de TE contendo os ácidos nucléicos. Em seguida os tubos foram incubados a $37^{\circ} \mathrm{C}$ por uma hora para a digestão do RNA. Para a eliminação da RNAse foi necessária nova extração com clorofórmio-alcool isoamílico (24:1), outra precipitação, agora sim de DNA (ácido desoxirribonucléico) puro, com etanol e ressuspensão em TE. As amostras de DNA foram quantificadas por espectrofotometria em aparelho GENEQUANT Pharmacia. 
As amplificações foram feitas em volume de $25 \mathrm{ml}$ contendo $20 \mathrm{mM}$ de Tris $\mathrm{Hcl} \mathrm{pH} \mathrm{8,4,} 50 \mathrm{mM}$ de $\mathrm{KCl}, 100$ $\mathrm{mM}$ de cada um dos 4 desoxinucleotídeos, $20 \mathrm{ng}(2 \mathrm{mM})$ de "primer" (10 pares de bases), 0,1\% Triton X-100, 1,8 mM de $\mathrm{MgCl}_{2}, 25 \mathrm{ng}$ de DNA molde de morango, 1,5 U da enzima Taq DNA Polimerase. A reação de amplificação foi feita em termociclador PTC-100 da M. J. RESEARCH INC. O programa iniciase com a pré-denaturação a $92^{\circ} \mathrm{C}$, por 2 minutos, seguida de 45 ciclos de 45 segundos a $94^{\circ} \mathrm{C}, 1$ minuto a $42^{\circ} \mathrm{C}$ e 2 minutos a $72^{\circ} \mathrm{C}$, com extensão final de 2 minutos a $72^{\circ} \mathrm{C}$. Os fragmentos amplificados foram separados em gel de agarose 1,6\% em tampão TBE (50 mM de Trisma base, $50 \mathrm{mM}$ de ácido bórico e 2,5 mM de EDTA sódico) à corrente elétrica de $100 \mathrm{~mA}$. O gel foi corado com brometo de etídeo $(10 \mathrm{mg} / \mathrm{ml})$ por 20 minutos, descorado em água corrente por 40 minutos e fotografado com filme polaroide 667 com filtro laranja em transiluminador de ultra violeta Macro Vue de $302 \mathrm{~nm}$.

Os "primers" utilizados foram escolhidos buscando-se procurar os que apresentavam capacidade de gerar número médio de fragmentos de DNA amplificados polimórficos (bandas), de alto peso e maior polimorfismo. Foram avaliados sessenta "primers" adquiridos da Operon Technologies INC, sendo vinte do Kit B, vinte do Kit $\mathrm{G}$ e vinte do Kit J. Baseado nestes resultados foram escolhidos os "primers" B 6, B 8, B 19, B 20, J 12 e J 16. Os "primers" G 2, G 5, G 11 e F 7 foram escolhidos porque apresentavam bom polimorfismo no trabalho de Gidoni et al. (1994) e os "primers" F 7 e G 11 porque deram bons resultados no trabalho de Parent \& Pagé (1995). Cada "primer" escolhido foi avaliado duas vezes com as vinte e seis cultivares. Dentre estes, foram escolhidos aqueles com melhor definição e com repetibilidade de resultados, que são os da Operon Technologies B 6 (TGCTCTGCCC), $\quad$ B 19 (ACCCCCGAAG), $\quad$ B 8 (GTCCACACGG), $\quad$ G 5 (CTGAGACGGA) e G 11 (TGCCCGTCGT). Estes "primers" geraram um total de setenta e três "marcadores" que foram utilizados na obtenção dos resultados deste trabalho. A partir destes "marcadores" foi possível construir um dendograma, onde é estimado o grau de similaridade entre as cultivares e o mapa de bandas que mostra a posição deles em cada cultivar, respeitando a mesma disposição de cultivares do dendograma. Entre os setenta e três "marcadores" gerados, foram escolhidas vinte com maor poder de discriminação dos "primers" B8, B19 e G5) com maior poder de discriminação. Com estes construiu-se o quadro de identificação e a chave dicotômica. Esta metodologia foi escolhida pois a utilização de poucos "marcadores" com capacidade de separar muitas cultivares facilita o trabalho de identificação. $\mathrm{O}$ dendograma e o mapa de bandas são úteis para obter o grau de similaridade entre cultivares e o quadro de identificação e a chave dicotômica são recursos para identificar cultivares.

A estimativa dos pesos moleculares dos fragmentos amplificados, utilizados como "marcadores", expressos em número de pares de bases, foi obtida diretamente nas fotografias das eletroforeses por comparação com o padrão de peso molecular 100 bp DNA ladder. A estimativa foi feita no software DNAFRAG (Schaffer \& Sederoff, 1981). Para a identificação das vinte e seis cultivares foram utilizados vinte "marcadores". Estes foram identificados por uma primeira letra e um número, que é a designação do "primer" que deu origem e por uma última letra que é a identificação do "marcador" e se refere ao número de pares de bases dos fragmentos amplificados. A descrição destes "marcadores" com o respectivo número de pares de bases, pode ser vista no quadro de identificação (Figura 1).

A análise dos dados moleculares foi baseada na presença ou ausência de bandas ( 1 ou 0 respectivamente) com o mesmo peso molecular. A partir dos géis obtidos foi construída uma matriz binária que originou a matriz de coeficientes de similaridade pelo método da similaridade qualitativa com o coeficiente de Jaccard. Para a formação dos dendogramas, as matrizes de coeficientes de similaridade foram analisadas pelo método do desempenho seqüencial de aglomeração hierárquica de grupos ("Sahn Clustering"), com o coeficiente do método do agrupamento pareado sem peso com significado aritmético (Rolph, 1992).

\section{RESULTADOS E DISCUSSÃO}

O dendograma formado, baseado no coeficiente de similaridade de Jaccard resultou em seis grupos de cultivares. Comparando-se as informações de origem das vinte e seis cultivares estudadas com o dendograma obtido, notamos que existe uma relação entre a origem das cultivares e o grau de similaridade exposto no dendograma. Podemos inferir que foram coerentes com a origem os grupos formados pelas cultivares Campinas, Agf 80, Jundiai, Piedade e Monte Alegre, pois estas (Camargo \& Passos, 1993) foram selecionadas no Instituto Agronômico de Campinas, com exceção de 'Agf 80' da qual se desconhece a origem, mas apresentou similaridade $100 \%$ com a cultivar 'Campinas'. O grupo formado pelas cultivares Lassen, Reiko, Chandler, Pajaro, Blackmore e Seascape só não é coerente com a origem porque a cultivar Reiko foi selecionada no Japão e não na California, como as demais (Thomas \& Goldsmith, 1945; Faedi et al., 1988 e Estados Unidos, Regents of the University of California, 1996a). O grupo formado pelas cultivares Obaira e Mantiqueira é coerente com os dados de origem pois ambas foram selecionadas no IAC, assim como o grupo formado pelas cultivares Fern e Oso Grande, ambas selecionadas na California (Faedi et al., 1988 e Estados Unidos, Regents of the University of California, 1996b). O grupo formado pelas cultivares Dover, Princesa Isabel e Dabreak não é coerente com a origem pois a cultivar 'Dover' foi selecionada na Florida (Howard \& Albregts, 1980), a cultivar Princesa Isabel foi selecionada no IAC (Camargo \& Passos, 1993) e ‘Dabreak' foi selecionada na California. $\mathrm{O}$ grupo formado pelas cultivares 'Florida Belle' e 'Selva' também não tem coerência com os dados de origem, pois a primeira foi selecionada na Florida (Howard \& Albregts, 1976), e a segunda na California (Faedi et al., 1988).

Inicialmente proposto por Powell et 


\begin{tabular}{|c|c|c|c|c|c|c|c|c|c|c|c|c|c|c|c|c|c|c|c|c|c|c|c|c|c|c|c|}
\hline Pr. & h & 1 & ? & 3 & 4 & 5 & 6 & 7 & 8 & 9 & 10 & 11 & 12 & 13 & 14 & 15 & 16 & 17 & 18 & 19 & 20 & 21 & 22 & 23 & 24 & 25 & 26 \\
\hline 38B & (5) & & $T$ & 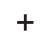 & 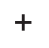 & ${ }^{\circ}$ & $T$ & 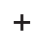 & 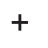 & & + & + & & $T$ & + & + & + & + & $T$ & + & 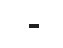 & $T$ & $T$ & + & + & + & + \\
\hline $8 G$ & & & - & - & & & 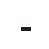 & & & & 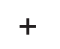 & 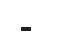 & & 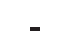 & 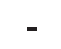 & & 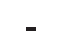 & 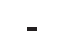 & & 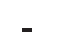 & - & 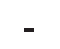 & 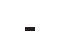 & - & _ & 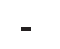 & - \\
\hline & & 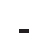 & + & + & 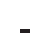 & & + & + & + & 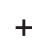 & & + & + & + & 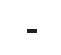 & + & + & + & + & 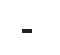 & 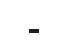 & + & + & + & + & + & + \\
\hline & 57 & - & - & - & - & - & - & - & - & - & - & - & & - & - & & - & - & - & - & - & - & & + & + & & - \\
\hline & & 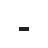 & - & 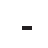 & - & - & - & 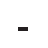 & 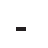 & 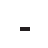 & 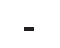 & 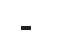 & & 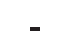 & 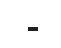 & 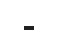 & 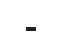 & & - & - & + & 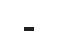 & & & & - & - \\
\hline 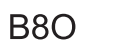 & 00 & & - & - & + & & - & - & 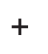 & + & + & 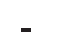 & + & + & + & + & + & ${ }^{\top}$ & - & ${ }^{\top}$ & 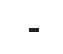 & + & + & + & + & + & + \\
\hline $19 \mathrm{~F}$ & 1250 & $T$ & - & - & + & + & - & - & - & + & + & - & 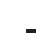 & + & - & - & + & - & - & - & - & + & + & - & + & + & - \\
\hline & & 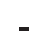 & 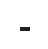 & 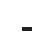 & - & - & - & - & 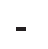 & 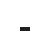 & 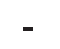 & 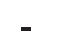 & & 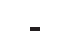 & 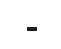 & 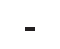 & 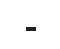 & - & - & - & 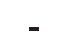 & 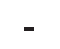 & + & & & 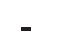 & + \\
\hline 19| & 062 & & - & - & - & . & - & - & & - & - & - & & - & - & - & - & + & - & - & - & - & - & - & - & & - \\
\hline 10 & 1028 & + & + & + & + & - & + & - & + & + & + & 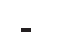 & . & - & + & - & + & - & - & - & - & 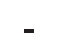 & - & - & + & - & + \\
\hline & & - & - & - & - & - & - & - & & - & - & - & & - & + & - & - & - & - & - & - & - & - & - & - & - & - \\
\hline $19 M$ & 11 & - & + & + & + & + & + & - & + & - & + & + & & 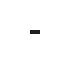 & - & - & & - & - & - & - & - & - & - & - & + & + \\
\hline & & - & + & + & + & - & - & - & - & - & + & 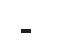 & 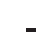 & - & 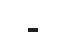 & - & - & - & - & - & - & - & - & - & - & - & - \\
\hline & & - & - & - & - & - & + & - & - & - & - & + & & - & + & - & - & - & - & - & - & - & - & - & - & - & - \\
\hline B19V & 564 & - & - & 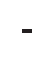 & + & + & - & - & - & - & - & 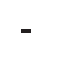 & 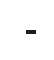 & - & - & - & - & - & - & - & - & - & - & - & - & - & - \\
\hline $19 W$ & 5 & - & - & - & - & - & - & - & + & - & - & + & - & - & - & - & - & - & - & - & - & - & - & - & - & - & - \\
\hline 554 & 976 & & + & + & + & + & + & + & + & + & + & + & + & + & + & + & + & + & - & + & - & - & + & + & + & + & + \\
\hline 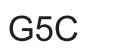 & 899 & & - & - & - & 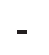 & - & - & - & - & - & - & . & - & - & - & + & - & - & - & - & - & - & - & - & - & - \\
\hline G5D & 843 & - & - & - & - & - & - & - & - & - & - & - & - & - & - & - & - & - & - & - & - & - & + & - & - & - & - \\
\hline $\mathrm{G} 5 \mathrm{~N}$ & 264 & - & - & - & - & & - & - & + & - & - & - & - & - & - & - & - & - & - & - & + & - & - & - & - & - & - \\
\hline
\end{tabular}

Figura 1. Quadro de identificação que separa as 26 cultivares testadas individualmente, onde "+" indica a presença do "marcador" e "--" a ausência. Na primeira coluna está a denominação do "primer" (pr), seguida da letra identificativa do "marcador" e na segunda o número de pares de base (pb) do "marcador" e nas outras 26 colunas, as cultivares em ordem crescente. Piracicaba, ESALQ, 1999.

al. (1991), o mapa de bandas é uma alternativa para apresentar os dados de "marcadores" (fragmentos de DNA amplificados de determinado peso) e a disposição deles nas cultivares utilizadas. Este método permite uma visão ampla da disposição dos "marcadores" e com ele é possível identificar o número de "marcadores" por cultivar e o número de cultivares com um determinado "marcador". Graham et al. (1996) utilizou este recurso em morangueiros. Neste trabalho foi construído este quadro com as vinte e seis cultivares e os mesmos setenta e três "marcadores" utilizados no dendograma. Neste quadro são colocadas as cultivares e a respectiva disposição de bandas começando de baixo para cima, com os "marcadores" que possuem somente uma banda nas vinte e seis cultivares, em seguida aqueles que possuem bandas em duas cultivares e assim por diante até, no final, aqueles "marcadores" que possuem bandas em todas as cultivares. A presença de produtos de amplificação está representada por espaços cheios e a ordem das cultivares é indicada exatamente como a gerada pelo dendograma. As designações da margem direita indicam a denominação dos "marcadores". O mapa de bandas deu indicações da disposição dos "marcadores" nas cultivares. A maior parte dos "marcadores" apresentou poucas bandas, pois 23,29\% dos "marcadores" apresentou uma banda e $68,50 \%$ apresentou até seis bandas.

Outra maneira de apresentar os dados de "marcadores" moleculares de RAPD é através de um quadro com o número suficiente de "marcadores" para identificar as cultivares. Gidoni et al. (1994) montaram um quadro de identificação para oito cultivares de morangueiro com os resultados da análise de RAPD e identificaram os fragmentos polimórficos de DNA ("marcadores") pelo número de pares de bases e pelo "primer" que deu origem. O quadro foi composto de oito cultivares e dez "marcadores". Neste trabalho foi possível montar este quadro de identificação (Figura 1) com as vinte e seis cultivares e vinte fragmentos polimórficos utiliza- dos como "marcadores", sendo seis do “primer" B 8, dez do "primer" B 19 e quatro do "primer" G 5. O quadro dá a disposição de todas as bandas de cada "marcador" em cada cultivar. No entanto, algumas cultivares podem ser identificadas por apenas alguns "marcadores". Assim, na tabela 1, descrevemos as cultivares e os respectivos "marcadores" seguidos do símbolo "+" quando a banda esta presente e do símbolo "." quando está ausente.

Parent \& Pagé (1995) propuseram uma chave dicotômica para identificar treze cultivares de morango do programa de certificação do Estado de Quebec, Canada, com resultados obtidos da análise de RAPD. Os autores montaram a chave dicotômica baseando-se em dez "marcadores" pertencentes a dois "primers". Neste trabalho, baseando-se nos mesmos "marcadores" utilizadas no quadro de identificação, construímos uma chave dicotômica para a identificação das vinte e seis cultivares analisadas (Figura 2). Alguns "marcadores" se destacaram nesta chave dicotômica, 


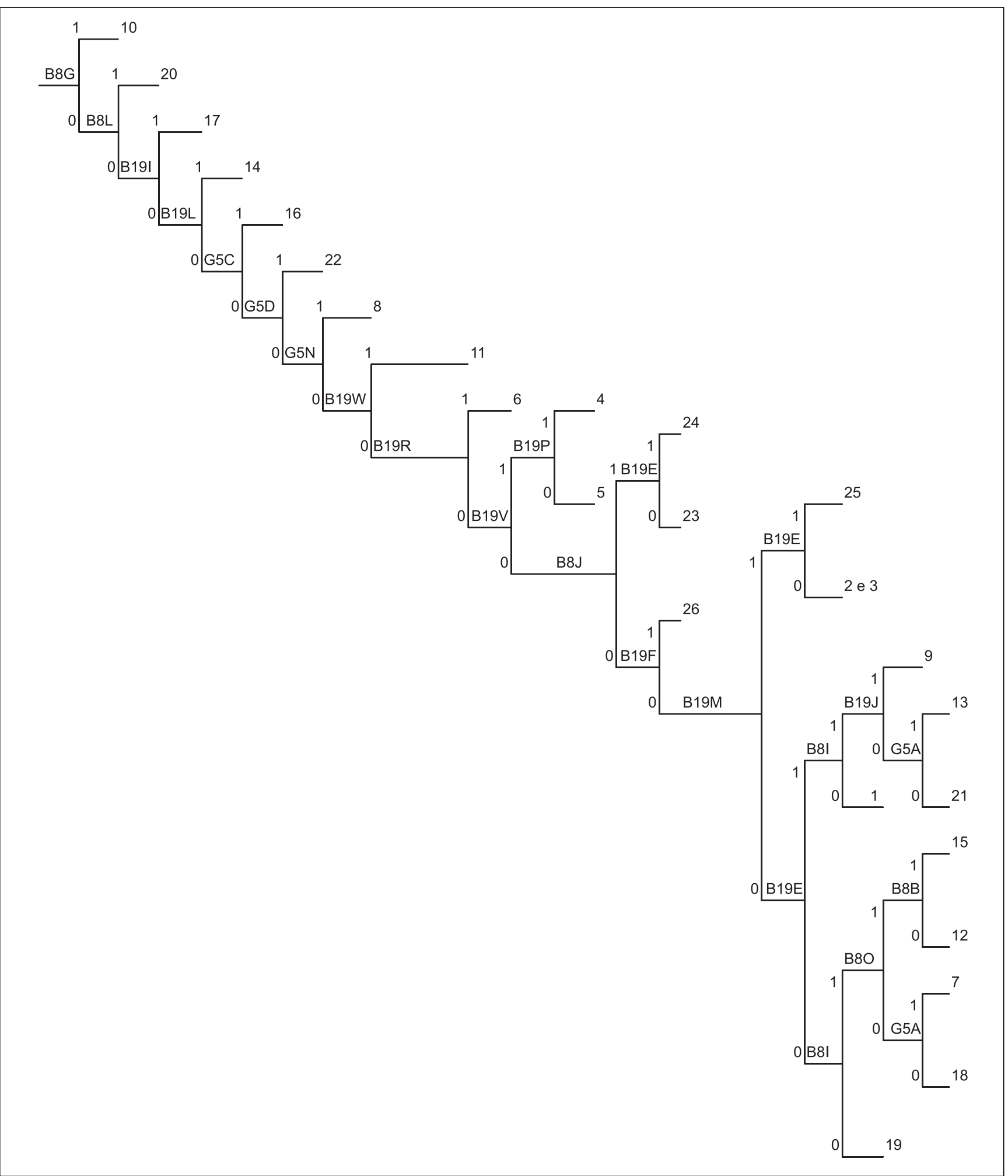

Figura 2. Chave dicotômica de identificação das cultivares expressos pelos números inteiros de 1 a 26 . O número " 1 " indica a presença da banda e o número "0" a ausência. As denominações com letras intercaladas de números são os "marcadores". Piracicaba, ESALQ, 1999.

pela importância na separação de cultivares. A banda do "marcador" B19M separa as cultivares Blackmore, Campinas e Agf 80 das demais, quando presente. A banda do "marcador" B19E, se presente, separa as cultivares Lassen, Dover, Reiko e Oso Grande de Mantiqueira, Obaira, Jundiai, Fern e Selva e, o mesmo "marcador" também separa Chandler de Pajaro e Blackmore de Campinas e Agf 80. Outro "marcador" que se destaca é o B8O pois a presença da banda separa as cultiva- res Mantiqueira e Obaira de Jundiai e Fern.

A caracterização de cultivares pode se basear nas diferenças de morfologia ou em diferenças nas moléculas de proteínas ou DNA. Esta última, denominada molecular, quando utiliza o DNA, 


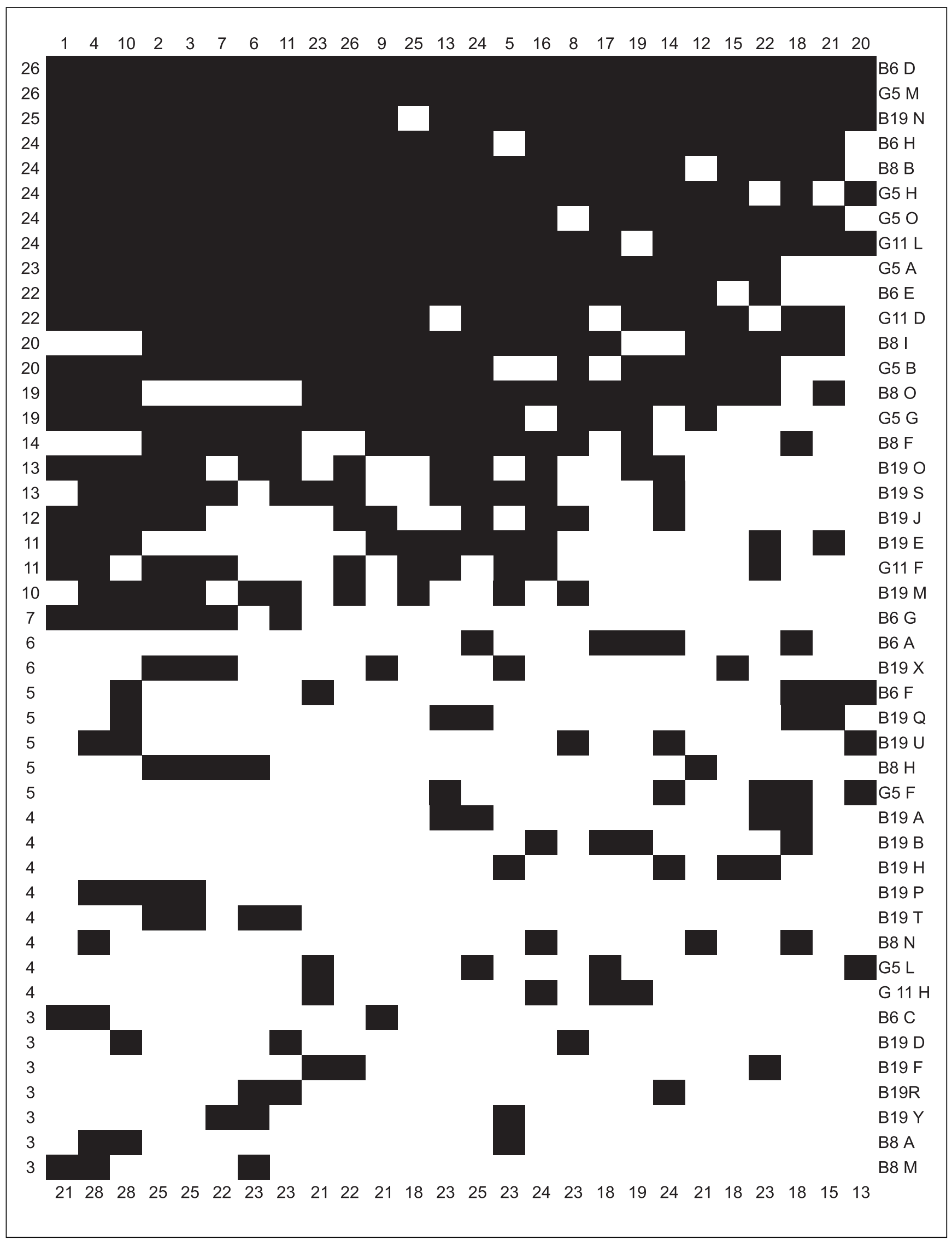

Figura 3. Mapa de bandas obtido com os dados de RAPD nas 26 cultivares com o índice de Jaccard. Os números acima do mapa indicam as cultivares, abaixo a quantidade de bandas da cultivar, na margem esquerda o número de bandas de cada "marcador" e na margem direita a denominação do “marcador”. Piracicaba, ESALQ, 1999. 


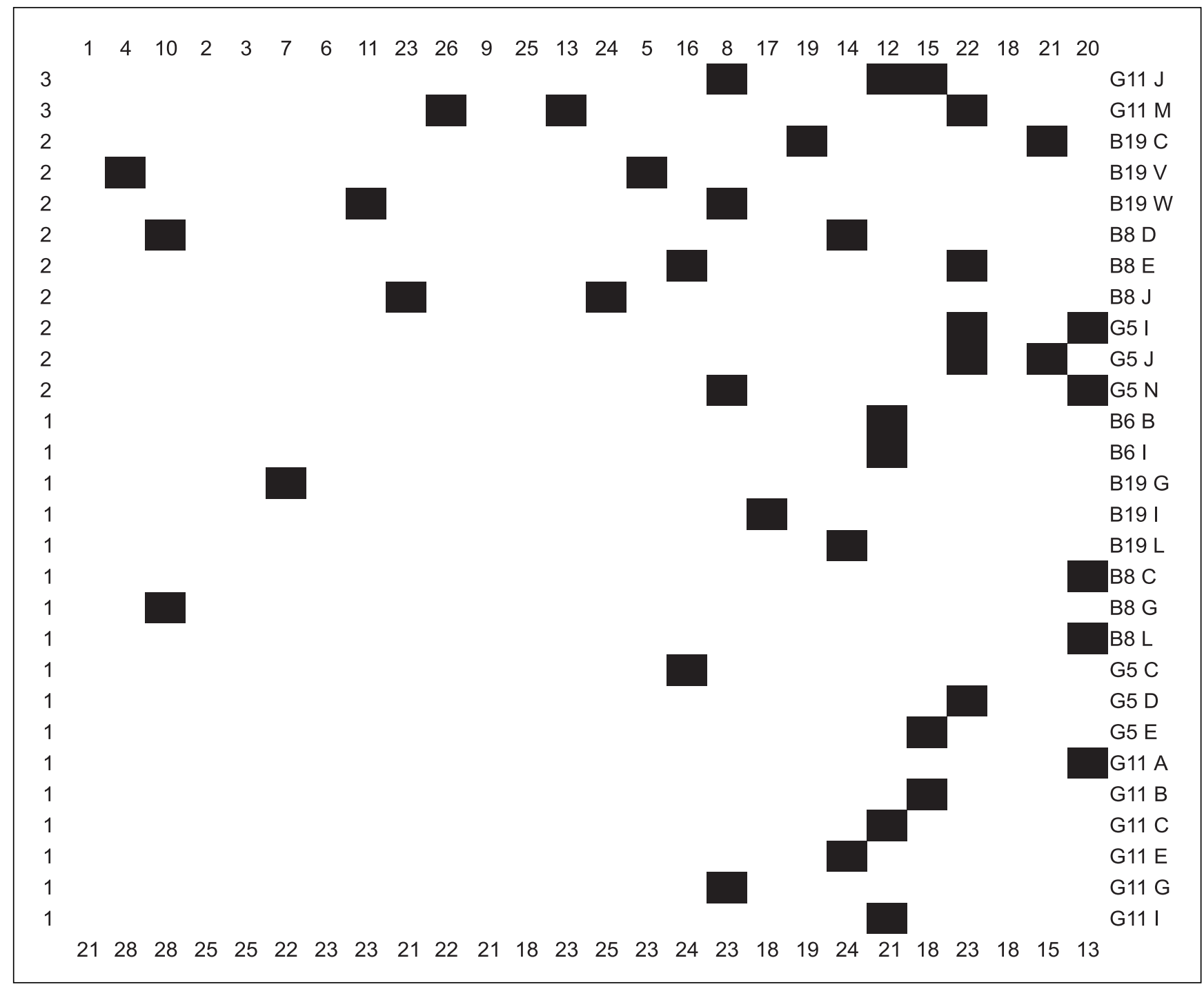

Figura 3. (Continuação)

pode ser realizada pelos métodos de RFLP, RAPD, AFLP, minisatélites ou microsatélites. Desse modo, a escolha de qual método utilizar vai depender das condições e recursos existentes disponíveis ao melhorista considerando as vantagens e desvantagens de cada um.

Ferreira \& Grattapaglia (1996) comentam que "marcadores" morfológicos existem em menor número, o que limita a cobertura do genoma, além disso são específicos para um determinado tecido o que impede a sua determinação quando há apenas alguma parte vegetativa da planta disponível. Os "marcadores" moleculares têm a vantagem de serem, em geral, neutros em relação a efeitos fenotípicos e têm mínimo ou nulo efeito epistático ou pleiotrópico. A desvantagem dos "marcadores" moleculares é a necessidade de alguns equipamentos, dependendo da técnica a ser utilizada, e o conhecimento prévio de quais "marcadores" são os mais adequados à cultura que está sendo utilizada. Considerando que a técnica de RAPD é relativamente barata, e que neste trabalho já foram detectados os "primers" B8, com os "marcadores" de 1793, 886, 752, 657, 593 e 468 pares de base (pb), o "primer" B19 com os "marcadores" de 1255, 1179, 1062, 1028, 990, 944, 855, 763,564 e 522 pb e o "primer" G5 com os "marcadores" de 976, 899, 843 e 264 $\mathrm{pb}$, como adequados à cultura do morangueiro, podemos inferir que é viável utilizar o método de caracterização molecular, por análise de RAPD, como outra opção a caracterização morfológica atualmente utilizada.

Entre as técnicas que utilizam o DNA, Santos (1994) comenta que a técnica de RAPD é mais rápida, mais simples, requer menor quantidade de DNA e é mais barata que a técnica de RFLP, no entanto pode apresentar baixa repetibilidade nos resultados. Considerando que neste trabalho foram adotadas as sugestões de uso de detergente e aumento da temperatura de anelamento para $42^{\circ} \mathrm{C}$ recomendadas por Levi et al. (1993) para obter dados com alta repetibilidade, podemos considerar a técnica de RAPD mais vantajosa. Ferreira \& Grattapaglia (1996) comentam que as técnicas de minisatélites exigem conhecimento prévio de qual sequência utilizar como sonda, e não se 
justifica o uso da técnica de microsatélite e AFLP em espécies com elevado nível de diversidade genética, detectável por outros métodos. A Fragaria X ananassa é uma dessas espécies, como ficou comprovado neste trabalho pela diversidade genética apresentada no dendograma. Por estas razões e pelos resultados obtidos através da análise de RAPD, que forneceu "marcadores" polimórficos para a identificação e formação de grupos de afinidade, esta técnica pode ser considerada a mais viável para a caracterização de cultivares de morango. Neste trabalho as cultivares Dabreak, Korona, Florida Belle, Dr Morèrè, Sequoia e Toyonoka apresentaram um "marcador" específico, demonstrando como "marcadores" RAPD podem ser aplicados com o propósito de discriminação.

Entre os mecanismos utilizados para ajudar a interpretar os resultados obtidos com marcadores de RAPD, verificamos que o dendograma é interessante para podermos propor o grau de similaridade entre as cultivares e a formação de grupos de cultivares semelhantes. O mapa de bandas é interessante quando se quer detectar quais os marcadores que ajudam na identificação destes grupos. O quadro de identificação pode ser utilizado quando o propósito é a identificação de cultivares, pois ele dá a disposição das bandas dos "marcadores" que realmente identificam as cultivares. A chave dicotômica tem a mesma função de uma chave dicotômica com base em dados morfológicos, ou seja, identificar cultivares com o mínimo de marcas possíveis e necessárias.

Passos (1982) verificou que havia ampla variabilidade entre as cultivares estudadas em seu trabalho e comentou que provavelmente grande parte era de origem genética. Neste trabalho foi demonstrado, pelos valores de similaridade obtidos nas análises moleculares, que há variabilidade entre as cultivares e, por estas análises terem como base o DNA, estas diferenças são de origem genética. Neste trabalho foram utilizados materiais com origem de programas de melhoramento de diversos países e o resultado não foi uma diversidade genética estreita como propunham Scott \& Lawrence (1975) e Sjulin \& Dale (1987). Esta maior diversidade genética pode ser consequência do fato do morangueiro, segundo Camargo \& Passos (1993), ter uma estrutura genética altamente heterozigota, devido aos vários niveis de ploidia e a origem híbrida da maioria das espécies, condição esta mantida pelo sistema de propagação vegetativa do morangueiro cultivado.

Estes resultados indicam que o morangueiro cultivado atualmente, apresenta diversidade genética, o que pode ser útil em programas de melhoramento e que, com o método de RAPD utilizando-se o dendograma e o mapa de bandas, é possível fazer inferências quanto a similaridade entre cultivares. Também é possível, utilizando-se do quadro de identificação e da chave dicotômica, identificar cultivares. No entanto, é interessante que trabalhos posteriores, com um número maior de "primers", determinem a absoluta especificidade dos "marcadores" para cada cultivar e uma análise mais abrangente e precisa do germoplasma do morangueiro cultivado e selvagem.

\section{AGRADECIMENTOS}

O presente trabalho foi realizado graças ao apoio da FAPESP, processo 96/1606-2, do CNPq e dos Departamentos de Horticultura e Genética da ESALQ/USP.

\section{LITERATURA CITADA}

BRINGHURST, R.S.; ARULSEKAR, S.; HANCOCK, J.F.; VOTH, V. Electrophoretic characterization of strawberry cultivars. Journal of the American Society for Horticultural Science, v. 106, n. 5, p. 684-687, 1981.

CAMARGO, L.S.; PASSOS, F.A. Morango. In: FURLANI, A.M.C.; VIEGAS, G.P. (Ed.) $O m e-$ lhoramento de plantas no Instituto Agronômico. Campinas: Instituto Agronômico, 1993, v. 1, cap. 11, p. 411-432.

ESTADOS UNIDOS. Regents of the University of California. Variety: 'Seascape' syn CN 49. Application n: 90/082. Plant Varieties Journal, v. 9, n. 4, p. 42, 1996a. /Resumo em CAB Abstracts on CD-ROM, 1996-4/98/

ESTADOS UNIDOS. Regents of the University of California. Variety: 'Oso Grande' syn C 43. Application n: 89/071. Plant Varieties Journal, v. 9, n. 4, p. 42, 1996b. /Resumo em CAB Abstracts on CD-ROM, 1996-4/98/

FAEDI, W.; ARCUTI, P.; LOVATTI, L.; RECUPERO, S.; TURCI, P. Monografia di cultivar di fragola. Roma: Istituto Sperimentale per la Frutticoltura, 1988. 36 p. (ISF, publicações, 296). FERREIRA, M.E.; GRATTAPAGLIA, D. Introdução ao uso de marcadores moleculares em aná- lise genética. 2 ed. Brasília: EMBRAPACENARGEN, 1996. p. 220. (EMBRAPACENARGEN Documento 20).

GIDONI, D.; ROM, M.; KUNIK, T.; ZUR, M.; IZSAK, E.; IZHAR, S.; FIRON, N. Strawberrycultivar identification using Randomly Amplified Polymorphic DNA (RAPD) Markers. Plant Breeding, v. 113, n. 4, p. 339-342, 1994.

GRAHAM, J.; McNICOL, R.J.; McNICOL, J.W. A comparision of methods for the estimation of genetic diversity in strawberry cultivars. Theoretical and Applied Genetics, v. 93, n. 3 p. 402-406, 1996.

HOWARD, C.M.; ALBREGTS, E.E. 'Florida Belle' Strawberry. HortScience, v. 11, n. 5, p. 519520, 1976.

HOWARD, C.M.; ALBREGTS, E.E. 'Dover' Strawberry. HortScience, v. 15, n. 4, p. 540, 1980. LEVI, A.; ROWLAND, L.J.; HARTUNG, J.S. Production of Reliable Randomly Amplified Polymorphic DNA (RAPD) Markers from DNA of Woody Plants. HortScience, v. 28, n. 12, p. 1188-1190, 1993.

NEHRA, N.S.; KARTHA, K.K.; STUSHNOFF, C. Nuclear DNA content and isozyme variation in relation to morphogenic potential of strabberry (Fragaria X ananassa) callus cultures. Canadian Journal of Botany, v. 69, n. 2, p. 239-244, 1991.

PARENT, J.G.; PAGÉ, D. Authentification des 13 cultivars de fraisier du programme de certification du Québec par l'analyse d'ADN polymorphe amplifié au hasard (RAPD). Canadian Journal of Plant Science, v. 75, n. 1, p. 221-224, 1995.

PASSOS, F.A. Caracterização de clones nacionais e introduzidos de morangueiro (Fragaria X ananassa Duch.), visando o uso imediato na horticultura e o melhoramento genético. Piracicaba, 1982. 116 p. (Dissertação mestrado) - Escola Superior de Agricultura “Luiz de Queiroz", USP.

PASSOS, F.A.; GRIDI-PAPP, I.L.; CAMARGO, C.E.O.; CHIAVEGATO, E.J.; DALL'ORTO, F.A.C.; NAGAI, H.; GODOY, I.J.; FAZUOLI, L.C.; VEIGA, R.F.A. Descritores mínimos para o registro institucional de cultivares: MORANGO. Campinas: IAC, 1994. 8 p. (IAC Documentos, 40). POWELL, W.; PHILLIPS, M.S.; McNICOL, J.W.; WAUGH, R. The use of DNA markers to estimate the extent and nature of genetic variability in Solanum tuberosum cultivar. Annals of Applied Biology, v. 118, n. 2, p. 423-432, 1991.

ROHLF, F.J. NTSYS-pc Numerical taxonomy and multivariate analysis system, version 1.7. Setanket, N.Y.: Exeter Software Publisher, 1992.

SANTOS, J.B. Emprego de marcadores moleculares no melhoramento de plantas. Horticultura Brasileira, Brasília, v. 12, n. 2, p. 282-286, 1994.

SCHAFFER, H.E.; SEDEROFF, R.R. Least squares fit of fragment size to gel mobility. Analytical Biochemistry, v. 115, p. 113-122, 1981. SCOTT, D.H.; LAWRENCE, F.J. Strawberries. In: JANICK, J. \& MOORE, N.M. Advances in fruit breeding. Indiana: Purdue University Press. 1975. p. 71-92.

SJULIN, T.; DALE, A. Genetic diversity of North American strawberry cultivar. Journal of the American Society for Horticultural Science, v. 112, n. 2, p. 375-385, 1987.

THOMAS, H.E.; GOLDSMITH, E.V. The Shasta, Sierra, Lassen, Tahoe and Donner strawberries. Berkeley: University of California, 1945. 90 p. (University of California. Bulletin, 690).

WILLIAMS J.G.K.; KUBELIK, A.R.; LIVAK, K.J.; RAFALSKI, J.A.; TINGEY, S.V.; DNA polymorphisms amplified by arbitrary primers are useful as genetic markers. Nucleic Acids Research, v. 18 , n. 22, p. 6531-6535, 1990. 